\title{
Analysis of the application of Insulating Vegetable Oil in electric power distribution transformers
}

\author{
Jadiel Caparrós da Silva ${ }^{1}$ \\ ${ }^{1}$ Universidade Federal do Tocantins, Course of Electrical Engineering, Palmas/TO, Brazil
}

Reception date of the manuscript: 01/07/2020

Acceptance date of the manuscript: 17/09/2020

Publication date: 18/09/2020

\begin{abstract}
Distribution transformers are present in large quantities in the electrical system, in addition to being essential equipment for delivering energy with quality and reliability to consumers. These distribution transformers have a dielectric insulation and a cooling system, with Insulating Mineral Oil (IMO) being the most used. However, the large-scale use of IMO carries a very high environmental risk, because in addition to its fossil origin (petroleum), it also has low biodegradability and is highly toxic and polluting to the environment. In view of this, substitution alternatives for the IMO began to be sought, where, over the years and with technological advances, Insulating Vegetable Oil (IVO) with characteristics similar to the IMO emerged, besides being highly biodegradable and providing an alternative sustainable development for the construction of transformers. Thus, the objective of this work is to carry out an analytical study on the characteristics and benefits of using the vegetable fluid for the equipment and the environment, in addition to comparing the efficiency and cost parameters of IVO and IMO according to current standards. As a contribution, this paper seeks to provide a broad theoretical foundation on IVO and IMO in order to provide conceptualization to agroenergy researchers.
\end{abstract}

Keywords-Electrical system, Distribution Transformers, Insulating Mineral Oil, Insulating Vegetable Oil, Sustainable development, Agroenergy.

\section{INTRODUCTION}

$\mathbf{N}$ owadays, the comfort and convenience brought by the daily use of electric energy have made it a necessity, whether at homes, in commerce or in industry. For consumers to be served with quality and reliability, energy goes a long way, including the stages of generation, transmission, distribution and commercialization, added to human effort and countless equipment [1]. Among these pieces of equipment, one of those considered essential for the proper functioning of the system is the transformer, present in enormous quantities, mainly in the electricity distribution networks. As they are located in the final stage of delivering energy to the customer, the distribution transformers must have a satisfactory level of performance in order to ensure the quality and reliability of the energy supplied [2]. It is also worth mentioning that they are present in large quantities, which involves a considerable cost, as it is an equipment that uses induction, them faults and defects end up interrupting the energy supply, resulting in undesirable levels of Equivalent Interruption Duration per Consumer Unit (DEC) and Equivalent Interruption Frequency per Consumer Unit (FEC) and operating costs [3]. Therefore,

Contact data: Jadiel Caparrós da Silva, jadiel@uft.edu.br maintenance for the proper functioning of this equipment and its optimized management are considered essential measures.

Among the components that make up the transformer is the insulation and cooling system $[4,5]$. The function of this system is to promote the dielectric insulation of the internal components of the transformer, as well as the cooling by heat transport, both functions performed by the use of an insulating oil. Of fossil origin, Insulating Mineral Oil (IMO) is the most used by manufacturers, and it can be paraffinic or naphthenic $[6,7,7]$. Since it comes from a non-renewable source, the use of IMO causes damage to the environment, in addition to emitting polluting gases in case of combustion or network failure. Like other sectors, the electric sector started to create an environmental awareness in its activities. In this parameter, the need arose to seek alternative sources such as the use of oilseeds for the production of insulating oil, in this case, Insulating Vegetable Oil (IVO) [8]. Its use in substitution to IMO has been studied, since IVO comes from a renewable source and has biodegradable characteristics.

Given the above, this work will explore updates in studies that refer to the use of IVO to replace IMO in transformers in order to define or guide whether its use is beneficial to the equipment and, consequently, to the electrical system. In this way, it will be argued about the importance of insulating oil with regard to the constructive and operating aspects of the transformer, as well as presenting the origin, manufacture and aspects of the IMO and IVO. It will address 
the environmental impacts caused by the use of IMO in order to bring information about technological development and the use of IVO's, and also, the parameters of efficiency and cost of IVO's will be compared taking as reference the commonly used IMO.

Based on the premise that currently the main contributors to the high levels of pollution and contamination of air, soil and water in the world are products from non-renewable fossil fuels (petroleum), it can be said that the IMO, widely used in the manufacture of conventional transformers, presents itself as a highly polluting agent since its manufacture [6]. Then, this work presents the proposal to elucidate the knowledge with regard to the technological advances for the manufacture of insulating oils substituted to the IMO that start from a renewable and biodegradable source and that bring an ecological proposal and less harmful to the environment, in this case, the IVO's.

\section{Methodology}

This is a bibliographic review based on scientific works published by recognized higher education institutions that deal with the subject in question and that correlate with the main thematic axis of this work. The methodical organization of this paper will start from the study of the characteristics of the transformer, more specifically the use of insulating oil in the composition of its dielectric insulation and refrigeration system. In sequence, the types of insulating oils commonly used in the manufacture of transformers will be presented, as well as their characteristics and peculiarities. Soon after, a more in-depth analysis will be made about the IVO's as an ecological proposal to replace the IMO. Finally, a comparison will be made between the parameters of the IVO's and the operation of transformers use using the IMO as a reference for the analysis.

\section{THEORETICAL FRAMEWORK}

In sequence, the theoretical framework used to develop the theme of this work will be presented.

\section{a. Distribution Transformers}

Distribution transformers have the function of lowering the voltage to levels that can be used by the final consumer. According to [9] distribution transformers represent one of the last stages for the generated energy to be used by the consumer. Thus, for the reliability of the electricity supply system to be completed, the required quality of large equipment must also extend to distribution transformers [10-12]. Figure 1 will depict the main components of a transformer. Two important points in Figure 1, regarding the insulating oil, is that it is stored in a reserve tank for temporary storage at the top. This tank has the purpose of expanding the transformer oil volume due to the temperature variations to which the transformer is subjected. Another important point is the purpose of the main tank, which in addition to the mechanical protection of the active part, it serves as a tank to be filled with insulating oil [13].

As described by [15], the composition of the transformer is made by means of a core, usually made of silicon steel and consisting of ferromagnetic material with characteristics of

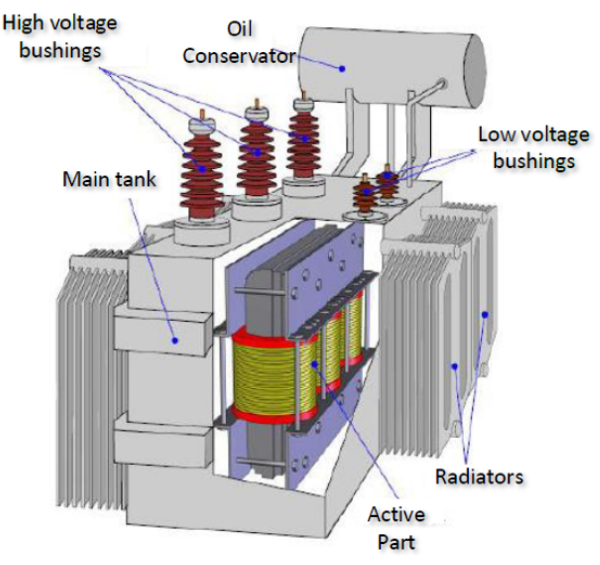

Fig. 1: Transformer Composition. Adapted from [14].

high magnetic permeability (greater than air permeability). In the internal components, aluminum or copper is used in the windings, and the coil is insulated by Kraft paper and fixed by wooden blocks [16,17]. All of these materials are in contact with the insulating oil $[12,13,18]$. Figure 2 shows the composition of the dielectric insulation system of the transformer and the flow direction of the insulating oil.

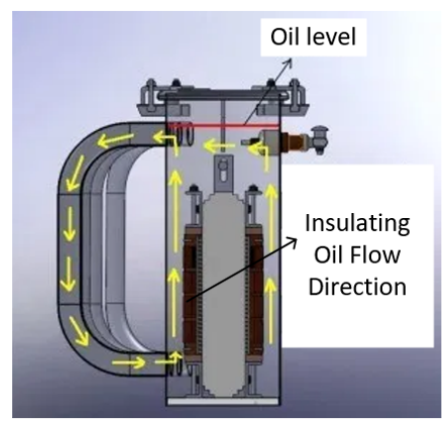

Fig. 2: Transformer isolation system. Adapted from [19]

The isolation system of a transformer is considered to be its main part, being basically constituted by an insulating liquid and a solid insulation [11]. This solid part is Kraft paper, which is practically the element responsible for defining the life of the transformer, as it does not have regenerative characteristics, different from the oil in use that can be treated or regenerated until it can be used again $[12,16,17,20]$.

In addition, according to [18], in the center of the transformer core, heat exchange occurs through conduction, which can be through air or oil. This heat exchange occurs between the outer surfaces of the core, windings, insulating fluid, between the insulating liquid and the inner walls of the tank and between the radiators and the external environment. There is also the so-called heat exchange for radiation, which occurs between the outer walls of the tank and the radiators and the air [12]. In addition, the most used transformer model is the one that uses oil inside the equipment, usually mineral oil, making it circulate through the materials with the function of cooling through heat exchanges, and isolating the internal components [10,13,21].

Reference [22] addresses the deterioration caused by the operation of the equipment, where during the operation of the transformers, various wear and aging processes can occur in the insulation system. To avoid machine downtime and, 
consequently, increase costs, and to guarantee the efficiency of the equipment, it is extremely important that preventive and predictive maintenance is carried out in order to ascertain the effects of thermal, chemical, electrical and mechanical fatigue, such as, hot spots, overheating, over-tension and vibration that are responsible for changes in the insulating system [20, 23, 24].

Based on this, Brazilian electric utilities are increasingly concerned with the maintenance of transformers, seeking to meet the requirements of the National Electric Energy Agency (ANEEL) [25], in addition to trying to reduce costs with repairs and replacements. Therefore, good resource management and the preservation of equipment through new techniques and effective maintenance, such as the simple collection of a small amount of oil from the network transformers for testing, appear as the best options in this scenario, as the characteristics presented by the oil can say a lot about the condition and the useful life of the equipment, being a parameter for intervention or not.

\section{b. Insulating Mineral Oil (IMO)}

The history of the transformer began in 1855 with a patent granted to Addenbrooke and Ferranti, and since 1890 the IMO has been used in transformers and remains, today, the most used liquid dielectric in transformers in association with insulating paper $[8,10,26]$. General Electric produced the first recognized application of the IMO in transformers in 1892 , turning the attention of the industry to determine the properties necessary for it to be used [26,27].

The popularity of the use of this oil occurred due to its low cost and its wide availability, obtained from the fractional distillation of oil, in addition to its excellent dielectric properties [10,26]. According to [28], IMO has been used as an insulating liquid in transformers for over a hundred years, reaching billions of liters of oil being used in electrical equipment worldwide.

The IMO consists basically of hydrocarbons [6] (molecules composed of Hydrogen and Carbon) with concentrations of other compounds, such as Sulfur, Nitrogen, among others [29]. Because of this composition, its leakage or spill can have significant environmental impacts, since it contaminates the soil and the water system, bringing economic impacts to the electric utilities [10,26]. Currently the mineral oil used can be naphthenic or paraffinic based, where naphthenic based is the most used, because it has good characteristics of thermal conductivity, high flash point, low cost of large-scale production, high regeneration capacity, great amount of physical-chemical tests, facilitating their maintenance, among others $[10,21,24]$. With regard to chemical parameters and their connections, the [7, 29, 30] show that the average oil molecules have between 19 to 23 carbon atoms arranged in a naphthenic structure. Naphthenes or cycloalkanes are closed-chain saturated hydrocarbons containing one or more rings, which may contain one or more side chains. The hydrocarbons present in the mineral oil composition are in the form of benzene rings combined with aliphatic rings. The structure of the naphthenic chain is depicted in Figure 3.

According to [7, 26, 29], the paraffins or alkanes material are saturated hydrocarbons of straight or branched open

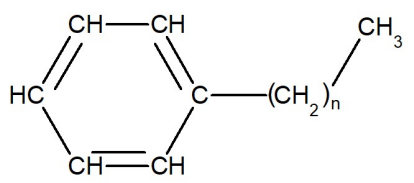

Fig. 3: Naphthenic Chain. Adapted from [30].

chain, thus, the paraffin-based oil has molecules arranged in a different structure from the naphthenic base. The structure of the paraffinic chain is shown in Figure 4.

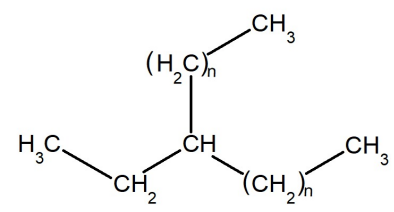

Fig. 4: Paraffinic Chain. Adapted from [30].

The parameters of mineral oil applied in transformers are divided into electrical (dielectric strength, electrical loss factor), chemical (water content) and physical (interfacial tension, viscosity, flash point and pour point) $[10,24,30]$. These mineral oils tend to form short-chain organic acids with by-products of degradation consisting of hydrocarbons that are harmful to the environment regardless of whether the oil used is paraffinic or naphthenic [27, 29]. These hydrocarbon compounds can migrate to the water table with rainwater infiltration, where one liter of oil can contaminate millions of liters of water, making it unfit for consumption $[21,26]$. The [29] show that the potential for contamination of a fluid is measured by its level of biodegradability, governed by the standard that determines these values, the Organization for Economic Cooperation and Development (OECD 301) [31], where for mineral oil, its level of biodegradability is around $10 \%$, that is, it is not very biodegradable. Another major problem observed in mineral oil is the flammability, because the ignition temperature is relatively low. For example, in transformer short-circuit failures, the product of oil combustion becomes dangerous and causes great air pollution [26,29].

After being put into operation inside the transformer, the IMO can still be influenced by factors such as temperature, oxidation and the presence of oxygen [24, 27, 32]. Such factors lead to physical-chemical changes in the properties of the oil, that is, deteriorations such as the loss of dielectric properties and the acceleration in the degradation of the insulating paper. So, according to [21,24,26,27,32], mineral oil can undergo an oxidation process, during the use of the transformer, damaging the Kraft insulating paper and resulting in the formation of acids, which can be measured using the neutralization index or acidity index $[16,17]$. Moreover, such compounds can polymerize and form sludge, which reduces the equipment's efficiency when deposited in the active part or in the heat exchangers $[6,29]$.

The moisture in the insulating liquids is also observed, in which the dielectric strength of the oil will decrease when the relative water saturation in the oil reaches 50\% [27]. For the IMO, saturation occurs in small concentrations in a range of 30 to $35 \mathrm{mg} / \mathrm{kg}$ of water [26]. In this way, moisture in 
the IMO acts as a catalyst in the decomposition of cellulose, reducing the useful life of the Wilhelm electrical equipment $[26,27]$. This moisture can also cause a corrosion process, since the composition of the IMO contains concentrations of corrosive sulfur compounds and this insulating fluid is in constant contact with the metallic part of the transformer [33].

Based on the aforementioned problems, attention was paid to the environmental issue, in addition to concern about the fact that oil is a finite resource [26]. In addition to this, even though it is cheap and quite efficient when new, the degradation of the IMO causes it to generate harmful by-products to the equipment and significantly lose its dielectric and refrigerant efficiency, thus losing its functionality and being able to mediate failures and losses [30]. It is worth mentioning that distribution transformers are subject to all types of weather, a factor that further contributes to the degradation of oil by temperature, humidity, occurrence of natural phenomena, among other factors, directly or indirectly [20]. Therefore, due to its large-scale use around the world, new less aggressive possibilities for the replacement of the IMO were then investigated [34].

\section{c. Insulating Vegetable Oil (IVO)}

Around 1999, IVO's suitable for use in electrical equipment (transformers) were developed [35]. This development was mainly driven by the environmental issue. Over the years, IVO has been adapted through specific processes and has received antioxidant additives in addition to pour point depressants, [27,28]. Chemically, IVO, used in transformers, is formed by molecules of acylglycerols, which originate from the condensation between fatty acids and glycerol (tri-alcohol), forming esters of fatty acids [8, 12, 36, 37]. In the case of IVO, three fatty acid molecules covalently associate with glycerol, forming esters of fatty acid called triacylglycerol $[12,12,37-40]$. Figure 5 shows the chemical structure of triacylglycerol.

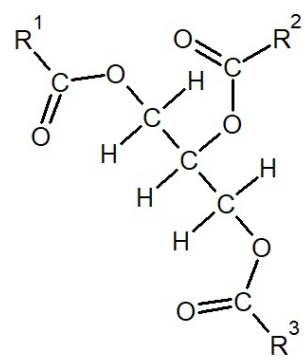

$$
\begin{aligned}
& R^{1}=R^{2}=R^{3} \\
& R^{1} \neq R^{2} \neq R^{3} \\
& R^{n}=12 \text { a } 18 \text { carbons }
\end{aligned}
$$

Fig. 5: Chemical structure of the triacylglycerol that makes up vegetable oil. Adapted from [30].

According to [10], the neutralization rates typical of the IVO are higher than those of the IMO, causing them to form long chains of fatty acids, which is less aggressive to the environment. Vegetable oils (crude) are always obtained from grains, by stripping, peeling, crushing, rolling, cooking, mechanical pressing or solvent extraction. Subsequently, this oil goes through the degumming, neutralization, bleaching and deodorization processes, obtaining the refined oil [8, 41]. The IVO has a much lower environmental impact compared to the IMO, as they come from a renewable source (soybeans, sunflower seeds, rapeseed and corn) and have high biodegradability. Therefore, in the event of a leak, the product degrades within a few days (28 days), which decreases the cost of electric utilities in relation to damage repairs [29, 35, 42, 42].

According to the Ministry of Agriculture, Livestock and Supply, the grain production trend only tends to increase in Brazil, with emphasis on corn and soybeans. According to the ministry's projections, highlighted by Table 1 , the cultivated area of these grains, mainly soybeans, will increase even more in the coming years, further leveraging this market niche and emerging as an opportunity for greater investment in IVO's [43].

TABle 1: BraZil: Planted AREa AND PRoJections For THE 5 MAIN GRAINS (THOUSAND HECTARES).

\begin{tabular}{cccccccc}
\hline \hline & $\mathbf{2 0 1 8} / \mathbf{1 9}$ & $\mathbf{2 0 1 9 / 2 0}$ & $\mathbf{2 0 2 0 / 2 1}$ & $\ldots$ & $\mathbf{2 0 2 4 / 2 5}$ & $\mathbf{2 0 2 5 / 2 6}$ & $\mathbf{2 0 2 6 / 2 7}$ \\
\cline { 2 - 8 } Rice & 1.697 & 1.557 & 1.516 & $\ldots$ & 1.092 & 989 & 882 \\
Bean & 2.978 & 2.853 & 2.748 & $\ldots$ & 2.329 & 2.224 & 2.119 \\
Corn & 17.242 & 17.366 & 17.490 & $\ldots$ & 17.984 & 18.108 & 18.231 \\
Soy & 35.802 & 36.678 & 37.596 & $\ldots$ & 41.452 & 42.424 & 43.395 \\
Wheat & 1.974 & 1.996 & 2.017 & $\ldots$ & 2.101 & 2.122 & 2.143 \\
TOTAL & $\mathbf{5 9 . 6 9 4}$ & $\mathbf{6 0 . 4 5 0}$ & $\mathbf{6 1 . 3 6 7}$ & $\ldots$ & $\mathbf{6 4 . 9 5 8}$ & $\mathbf{6 5 . 8 6 7}$ & $\mathbf{6 6 . 7 7 1}$ \\
\hline \hline
\end{tabular}

As can be seen from Table 1, Brazil has the capacity to generate renewable resources on a large scale and rich in oilseeds. The justification for the low use of IVO in the manufacture of transformers is due to its oxidation stability, pour point, permissiveness and distinct viscosity $[8,32,44]$. However, this scenario has changed due to the environmental issue that has been of increasing concern to the world community [33].

The first commercial product launched on the market was BIOTEMP ${ }^{\circledR}$ [45], whose patent was applied for in the United States of America (USA), in September 1999, by the company Asea Brown Boveri (ABB). This product had sunflower oil based fluid with an oleic acid content greater than $80 \%$. Waverly Light \& Power and Cooper Industries have won two other patents for the development of insulating fluids obtained from soybean oil [33]. In the beginning of 2007 , using $100 \%$ Brazilian technology, BIOVOLT ${ }^{\circledR}$ oils were produced and commercialized by the company Mineraltec [27]. Later, in the same year, it was notified that around 410 isolated transformers with IVO were in operation in the primary voltages of 440 to 230.000 volt (V) and of nominal power between 10 to 40.000 kilo-volt-ampere (kVA) [38].

An important chemical characteristic of IVO are natural esters, which have a high affinity for water, contributing to the increase in the useful life of solid insulation, which is directly related to the reduction of costs for electric utilities $[26,28,37,39,40,46,47]$. This statement regarding the chemical characteristics of IVO was made through the results of IVO aging studies, which showed that the insulating paper has its life extended in the presence of vegetable-based oils [23, 28, 48]. Another study conducted by [38], shows that the insulating paper has its life extended in the presence of vegetable oils over the years. In 2009, [27] produced test results using a hydrolysis mechanism that favored the 
displacement of more water molecules from the paper to the insulating fluid, promoting the drying of the insulating Kraft paper and maintaining its chemical balance, resulting in the extension of its useful life [16, 17, 48]. And yet, according to $[28,49]$, the fluids of natural esters present different dielectric performance, with a dielectric strength of the same magnitude as that of IMO. However, water does not significantly affect the dielectric strength of IVO, unlike IMO due to its chemical properties, giving superiority to IVO with greater resistance to high temperatures [8, 28, 35, 39, 40, 49].

Another important characteristic of the IVO is that it is only considered flammable at temperatures above $340^{\circ} \mathrm{C}$, therefore, it is conceptualized as a safety fluid with less fire incidence, and with the smoke from its combustion being less dense, and less harmful, when compared to mineral oil $[8,27,50]$. Therefore, the fossil origin of the IMO further strengthens its superior contamination capacity compared to the IVO, as well as its aging, which is much more detrimental to the useful life and performance of the equipment than that of the IVO [8, 21, 23]. Another important parameter of vegetable oil is electrical permittivity [35]. In a transformer, the winding insulation system makes the distribution of requests inversely proportional to the material's electrical permittivity $[4,45]$. Thus, the greater the electrical permissiveness of the esters, the lower the electrical demand on the windings as the winding insulation system consists of paper and oil $[39,46]$. This characteristic allows isolated transformers with IVO to withstand greater overloads than those using IMO $[35,36]$. Contributing to environmental sustainability, another possible factor of the IVO is that at the end of its useful life, it can be reused for the production of biofuels [29].

One of the characteristics that can be seen as negative of the IVO is that it has slightly higher viscosity in relation to the IMO, reducing the cooling power of the IVO, since the heat exchange with the environment becomes slower [4]. However, commercial IVO's have additives that, despite increasing their prices, make the IVO to match the IMO in this regard [27].

Because it is highly toxic, disposal of the IMO cannot be carried out in any way. The process requires high costs to those responsible, in addition to the fact that any failure results in serious punishments with the environmental agencies. The IVO at the end of its useful life, on the other hand, becomes a raw material for the production of biofuels, in addition to being highly biodegradable, reducing environmental risk and its cost in the long run [27].

Most electric utilities use vegetable oil in transformers, for example Companhia Energética de Minas Gerais (CEMIG) [51], Companhia Paulista de Força e Luz (CPFL) [52] and Group Energisa [53]. One of the main characteristics of these transformers on the market is the green color used by the manufacturers in order to give strength to the ecological and sustainability message $[8,35]$. Figure $6 a$ shows a model of distribution transformer manufactured by Ecological Transformers Itaipu using vegetable oil in its composition [54]. Figure 6b shows a 25 Mega Volt Ampere (MVA) transformer installed in the CEMIG electric utilities substation, filled with vegetable oil from BIOTEMP ${ }^{\circledR}$, and produced by $\mathrm{ABB}$ [51].

As can be seen, the use of IVO in transformers, does not

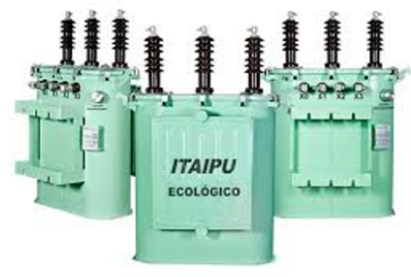

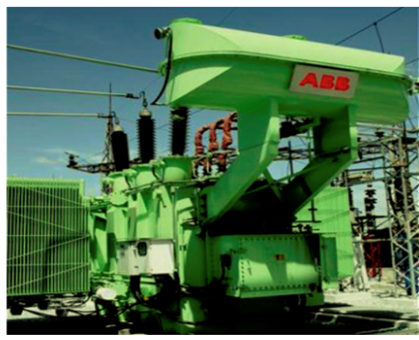

Fig. 6: Transformers that use vegetable oil as an insulator.

result in power limitations and has no usage limits, and can be used for both low power (distribution systems) and high power (transmission systems).

\section{d. Standardization for insulating oils}

The Brazilian Agency for Technical Standards (ABNT) is the body responsible for presenting guidelines for the use of IVO in electrical equipment in Brazil. The NBR $15422[55,56]$ it specifies the acceptable chemical and physical parameters of the IVO, before coming into contact with the equipment.

Most manufacturers of IVO's meet the specification of the ABNT NBR 15422 standard [55], however, the same performance is not expected for these oils against aging agents, since oxidation stability is related to the chemical composition of the base oil, the concentration and type(s) of additive(s) added by the manufacturers [23, 27, 32, 48]. Therefore, the IEEE published a document entitled as IEEE Guide for the acceptance and maintenance of fluids from natural esters in transformers (C57.147-2018) [46]. This guide is intended to standardize the indexes for maintaining the IVO after using and energizing electrical equipment containing oil [46]. This IEEE Guide also includes the description of the tests to be carried out, filling practices, handling and maintenance of insulating fluids during use, in addition to bringing all the reference values for the IVO specifically after energizing new equipment, such as also during use [27, 39, 40, 46, 49,56].

It is possible to notice in Table 2 that some characteristics change from the reference value compared to the new IVO without contact with the equipment. They are: dielectric strength, dielectric loss factor and water content.

For dielectric strength, the limit values shown apply to insulating vegetable oils $[8,13,56]$. Due to differences in their chemical composition, certain values are significantly different from the limits for the IMO. Typical values for each fluid can be obtained from the manufacturer. If the test results, although in accordance with this table, are significantly different from the typical published values, it is recommended that the oil manufacturer be contacted $[35,46,48]$.

Table 3, on the other hand, makes references to desired values during the maintenance of equipment in operation with the use of IVO, since changes outside this standard are indicative of the need for intervention in this equipment $[35,46]$.

The main factors to be monitored are: viscosity, neutralization index and dielectric loss factor [46]. And for transformers where IMO is replaced by IVO, in addition to 
TABLE 2: TEST LIMITS FOR NEW NATURAL ESTER FLUIDS RECEIVED IN NEW EQUIPMENT.

\begin{tabular}{|c|c|c|}
\hline \multirow{2}{*}{ Test and ASTM method } & \multicolumn{2}{|c|}{ Value for voltage class } \\
\hline & $\leq 69 \mathrm{kV}$ & $69 \mathrm{kV} 230 \mathrm{kV}$ \\
\hline \multicolumn{3}{|l|}{$\begin{array}{l}\text { Dielectric strength } \\
\text { ASTM D1816kV,minimum, }\end{array}$} \\
\hline $1 \mathrm{~mm}$ gap & 25 & 30 \\
\hline $2 \mathrm{~mm}$ gap & 45 & 52 \\
\hline $\begin{array}{l}\text { Dissipation factor, ASTM D924, } \\
\% \text {, maximum, } 25^{\circ} \mathrm{C}\end{array}$ & 0.5 & 0.5 \\
\hline $\begin{array}{l}\text { Color, ASTM D1500, ASTM } \\
\text { units, maximum }\end{array}$ & L1.0 & L1.0 \\
\hline Visual examination, ASTM D1524 & $\begin{array}{l}\text { Bright and } \\
\text { clear }\end{array}$ & $\begin{array}{l}\text { Bright and } \\
\text { clear }\end{array}$ \\
\hline $\begin{array}{l}\text { Neutralization number (acidity), } \\
\text { ASTM D974, mg KOH/g, maximum }\end{array}$ & 0.06 & 0.06 \\
\hline $\begin{array}{l}\text { Water content, ASTM D } 1533 \text {, } \\
\mathrm{mg} / \mathrm{kg} \text {, maximum }\end{array}$ & 300 & 150 \\
\hline Fire point, ASTM D92, ${ }^{\circ} \mathrm{C}$ & 300 & 300 \\
\hline $\begin{array}{l}\text { Kinematic viscosity, ASTM D445, } \\
\mathrm{mm} 2 / \mathrm{s}(\mathrm{cSt}) \text { at } 40^{\circ} \mathrm{C} \text {, maximum }\end{array}$ & 50 & 50 \\
\hline
\end{tabular}

TABLE 3: CharaCteristics OF THE IVO IN USE IN THE EQUIPMENT.

\begin{tabular}{|c|c|c|c|}
\hline \multirow{2}{*}{ Test and ASTM method } & \multicolumn{3}{|c|}{ Value for voltage class } \\
\hline & $\leq 69 \mathrm{kV}$ & $69 \mathrm{kV} 230 \mathrm{kV}$ & $230 \mathrm{kV}$ and above \\
\hline $\begin{array}{l}\text { Dissipation factor, } \\
\text { ASTM D } 924 \text {, in } 25^{\circ} \mathrm{C}, \%\end{array}$ & $\geq 3$ & $\geq 3$ & $\geq 3$ \\
\hline $\begin{array}{l}\text { Water content, } \\
\text { ASTM D1533, mg/kg }\end{array}$ & $\geq 400$ & $\geq 200$ & $\geq 150$ \\
\hline $\begin{array}{l}\text { Viscosity increase } \\
\text { ASTN D } 445, \text { at } 40 \mathrm{oC}, \%\end{array}$ & $\geq 10$ & $\geq 10$ & $\geq 10$ \\
\hline $\begin{array}{l}\text { Neutralization Index, } \\
\text { ASTM D974, mg KOH/g }\end{array}$ & $\geq 0,3$ & $\geq 0,3$ & $\geq 0,3$ \\
\hline Fire point, ASTM D92, ${ }^{\circ} \mathrm{C}$ & $\leq 275$ & $\leq 275$ & $\leq 275$ \\
\hline Inhibitor Content & $\gamma$ & $\gamma$ & $\gamma$ \\
\hline
\end{tabular}

the factors mentioned, it is important to monitor the flash point of the oil due to IMO impregnation from previous use and the water content in the oil $[13,57]$.

\section{e. Technology and research developed}

There are some important studies done in Brazil on the use of IVO replacing of IMO. This subsection will address the main studies that achieved important results.

In a dissertation presented to the master's program in agroenergy at the Federal University of Tocantins, entitled: "Estudo de viabilidade técnica na utilização de óleo vegetal como agente isolante e refrigerante em substituição ao ólea mineral em transformadores de distribuição" [34], sought to carry out the direct replacement of IMO by IVO (with commercial soy-based insulating fluid: Envirotemp FR3) in a $15 \mathrm{kVA}, 220 / 380-13800 \mathrm{~V}$ three-phase distribution transformer, without constructive adjustments after carrying out the cleaning and drying process of the tank and internal components. Three types of tests were carried out according to the current regulations $[46,48,55]$, seeking to visualize the physical-chemical and electrical characteristics, such as the kinematic viscosity, neutralization index and dielectric strength of the IVO after the replacement of the IMO in the transformer. All tests were performed in triplicate, that is, they were repeated 3 times with the final result being the arithmetic mean of the values obtained in the measurements and shown in Table 4.

TABle 4: Results of RePlacing IMO With IVO.

\begin{tabular}{cccc}
\hline \hline & \multicolumn{3}{c}{ Tests performed } \\
\cline { 2 - 4 } & $\begin{array}{c}\text { Kinematic } \\
\text { viscosity }\end{array}$ & $\begin{array}{c}\text { Neutralization } \\
\text { index }\end{array}$ & $\begin{array}{c}\text { Dielectric } \\
\text { strength } 40^{\circ} \mathrm{C}\end{array}$ \\
\hline 1st measurement & $35 \mathrm{cSt}$ & $0.05 \mathrm{mgKOH} / \mathrm{g}$ & $58.5 \mathrm{kV}$ \\
2nd measurement & $35.3 \mathrm{cSt}$ & $0.05 \mathrm{mgKOH} / \mathrm{g}$ & $47.1 \mathrm{kV}$ \\
3rd measurement & $34.9 \mathrm{cSt}$ & $0.05 \mathrm{mgKOH} / \mathrm{g}$ & $32.9 \mathrm{kV}$ \\
Average & $\mathbf{3 5 . 0 6} \mathbf{~ c S t ~}$ & $0.05 \mathrm{mgKOH} / \mathrm{g}$ & $\mathbf{4 6 . 1 6 ~ \mathbf { ~ V }}$ \\
\hline \hline
\end{tabular}

When comparing the results obtained with the ABNT and IEEE standards, it is possible to see that they are all in compliance with the regulations and that this insulating fluid meets the necessary requirements for use in replacement of the IMO in the distribution transformers. It is worth mentioning that in this study, the kinematic viscosity refers to the fluidity of the oil, that is, its ability to move inside the equipment and, consequently, to transport the heat from the active part to the walls of the transformer tank. The neutralization index refers to the presence of acids in the oil resulting from its degradation, which can damage the Kraft paper and consequently negatively reach the efficiency of the insulation and decrease the useful life of the equipment, that is, the lower the amount of harmful acids, the smaller the amount of hydroxide needed to neutralize it in the test and greater equipment longevity $[16,17]$. As for dielectric strength, this parameter refers to the electrical insulating capacity of the fluid, which provides safety and protection to the equipment, especially when working with high voltage levels. In this last parameter, when observing the three measurements, it is possible to notice a drop in the obtained value. This is due to the short oil rest interval between one measurement and another (4 minutes), but still the arithmetic mean of the measurements exceeded the 30kVA [34], recommended by NBR 15422 [55] and the IEEE Guide - C57.147-2018 [46].

Another relevant point, presented by [34,50], are the high flash and combustion points of the IVO used (Envirotemp FR3), around $330^{\circ} \mathrm{C}$ and $360^{\circ} \mathrm{C}$ respectively. This brings him the classification of safety fluid or high combustion fluid, with a very low level of fire risk, even compared to Askarel, widely used in the past as an electrical insulating fluid, but banned in Brazil since the 1980s, due to its high toxicity and for being a carcinogenic product.

Presented to the Postgraduate Program in Engineering and Materials Science at Federal University of Paraná, the dissertation with the title: "Avaliação do potencial de aplicação de óleos vegetais como fluidos isolantes em transformadores de distribuição da rede elétrica" [10], shows test and results made through vegetable insulating oils without the presence of additives, commercial IVO's, as well as mineral oil itself. The oils tested were: vegetable oil based on soy, vegetable oil based on sunflower, vegetable oil based on rice, vegetable oil based on castor oil, commercial vegetable oil based on soy, commercial vegetable oil (mixture of oils) and commercial mineral oil. 
With all tests duly standardized, [10,21, 58] observed that only commercial items met the regulatory requirements for use as an insulating fluid. All IVO's without presence of additives in the constitution (non-commercial) failed in one or more parameters, where sunflower oil was the closest to the ideal, failing only in the water content in its constitution, a characteristic related to the tendency to oil oxidation $[10,21,32]$.

With regard to the costs of dielectric fluids, the work of [58-60], carried out with the Cooperativa Energética Cocal (COOPERCOCAL), compares the costs of new and regenerated mineral insulating oils, in addition to an imported brand (IVO A) and another (IVO B) of insulating vegetable oil. Table 5 shows the purchase costs for the insulating fluids mentioned. It is worth mentioning that these values may vary according to the characteristics of the market and the price of the dollar.

TABLE 5: General COSTS OF INSULATING OILS.

\begin{tabular}{cc}
\hline \hline OIL TYPE & COST (R\$/L) \\
Vegetable oil A (new) & 22,75 \\
Vegetable oil B (new) & 6,00 \\
Mineral oil A (new) & 5,00 \\
Mineral oil B (regenerated) & 3,00 \\
\hline \hline \multicolumn{2}{c}{ Adapted from[59] }
\end{tabular}

When analyzing the costs of purchasing, with two COOPERCOCAL suppliers, new transformers using IMO and IVO, it was found that the costs of new equipment supplied with IVO have a higher cost compared to those supplied with IMO. For a more detailed analysis, with the information provided by COOPERCOCAL, $[59,60]$ made a forecast of the cooperative's investment for the acquisition of new transformers with IVO insulation, and it was possible to observe that the acquisition costs predicted were $22 \%$ higher for transformers supplied with IVO.

Also based on data provided by COOPERCOCAL, [59] estimated costs for replacing the IMO with regenerated IMO and IVO during the maintenance of the distribution transformers. It was possible to note that the cost of replacing with IVO is double the use of regenerated IMO, a factor that can be corrected by the benefits of using vegetable oil for the life of the equipment and safety for the environment. The Table 6 shows the cost related to products and services of the insulating fluid replacement process.

TABle 6: COST RElATED TO PRODUCTS AND SERVICES OF THE INSULATING FLUID REPLACEMENT PROCESS.

\begin{tabular}{cccc}
\hline \hline $\begin{array}{c}\text { Transformer } \\
\text { (Power) }\end{array}$ & $\begin{array}{c}\text { Mineral Oil (1) } \\
\mathbf{R} \$\end{array}$ & $\begin{array}{c}\text { Vegetable Oil (2) } \\
\mathbf{R} \$\end{array}$ & $\begin{array}{c}\text { Investment (3) } \\
\mathbf{R} \$\end{array}$ \\
\hline $30 \mathrm{KVA}$ & 700,00 & $3.200,00$ & $2.500,00$ \\
$45 \mathrm{KVA}$ & 900.00 & $5.580,00$ & $4.680,00$ \\
$75 \mathrm{KVA}$ & 500.00 & $3.760,00$ & $3.260,00$ \\
1112.5 KVA & 100,00 & $1.438,00$ & $1.338,00$ \\
TOTAL & $\mathbf{2 . 2 0 0 , 0 0}$ & $\mathbf{1 3 . 9 7 8 , 0 0}$ & $\mathbf{1 1 . 7 7 8 , 0 0}$ \\
\hline \hline
\end{tabular}

(1) Amounts obtained from the responsible service provider.

(2) Estimated values based on the case study values.

(3) Investment difference in the replacement of IMO by IVO. Source: Adapted from [59]

It was then concluded that the IVO replacement process is much more expensive, since emptying, cleaning, drying and thermo-vacuum filling of the transformer that previously contained the IMO are necessary, processes that are not necessary for filling with the regenerated IMO [59].

In a case study carried out by a company that works with the direct handling of IMO, it was possible to attest, through the answers in an interview, with the person responsible for the environmental issues of the company, in addition to the observations made in the workplace, that the possible risks to soil, water and air contamination, as well as accidents during handling are underestimated. That is, even with all the mobilization focused on environmental issues, it is possible to note that there is a lack of greater awareness of the market involved around the IMO. This happens also because of the price difference which is still very large (note Table 6). As described by [60,61], even taking into account and following the recommendations in the event of an oil spill, the environmental impact caused is still very large, and just trying to minimize the damage is not enough, because in addition to the environmental damage, there is a great financial loss of damage recovery.

The last work highlighted here was done by [62], who highlights the advantages of using IVO, as well as its limitations such as the need for viscosity correction. However, what draws attention is the questioning of the author about competitiveness with the food industry. It really is something to consider, but it cannot be said that this would be an obstacle, because as shown in table 1 the forecast of grain production, mainly of soybeans, increases year after year, in addition to the fact that studies and techniques for the production of IVO be developed from the reuse of edible oils, which would solve other problem: the disposal of used oil and the availability of raw material for IVO's.

\section{DisCUSSION}

In view of what was observed in the course of the work, it is possible to note that the central treatment always revolves around sustainable development, in this case for the production and use of insulating fluids that are less harmful to the environment. This theme fits more than perfectly in the reality faced by humanity today, where each advance obtained and innovation implemented can mean another relief for nature and consequently for humanity. The IVO presents itself with an interesting ecological proposal since its origin, unlike the IMO, of fossil origin, highly polluting and toxic to the environment. In addition, the fact that the latest technological advances applied to the production of IVO have made it more efficient and superior to the IMO in some parameters, making it gain more space in the market, even though it initially has a higher commercial value.

The use of IVO gives the equipment a longer useful life due to its greater affinity for water, acting indirectly to dry Kraft paper through hydrolysis, in addition to having a greater resistance to moisture saturation, unlike the IMO. It is also worth mentioning that the IVO does not contain sulfur and petroleum derivatives in its composition like the IMO, with the oil degradation process it will not polymerize and form conductive and corrosive sludge that ends up damaging the Kraft paper and the active parts equipment, reducing its useful life and acting as a catalyst for accident failures.

Another characteristic in which the IVO is superior to 
the IMO is its flash and combustion points, above $300^{\circ} \mathrm{C}$, which end up giving it the classification of safety fluid for use at high temperatures. Because it has low flash and combustion points (around $150^{\circ} \mathrm{C}$ ), IMO is a fluid that is very susceptible to accidents, where any network failure or external interference that causes an increase in temperature can cause the transformer to combust and even an explosion is caused, which may result in even greater losses to the electric utilities than just replacing the equipment, in addition to the simple fact that burning the IMO releases harmful gases into the atmosphere. In terms of biodegradability, a small amount of IMO spilled into water or soil has a highly polluting and toxic effect, which can drain and contaminate millions of liters of water from the springs, making them unfit for consumption and taking years for partial degradation to occur, very different from IVO, which practically does not offer environmental risk, being totally degraded in nature in a maximum of 28 days. Some normative parameters cause most of the natural vegetable oils to fail because they do not meet all the criteria for use, the main ones being their kinematic viscosity higher than the reference values and the large amount of water in their chemical composition [50,58].

However, manufacturers developed techniques for treating these oils and producing commercial IVO's with the addition of additives for drying and fluidity gain by the oil, which, in addition to adapting it to the normative indices, made it competitive with the IMO in terms of efficiency. Unfortunately, the additions of these additives together with the cost of production make their market value higher than that of the IMO, serving as a barrier to large-scale adhesion. But before generating any conclusions about unfeasibility due to high implementation costs, it is necessary to raise some interesting points observed with the use of IVO:

- The useful life of the equipment is prolonged, being able to increase the intervals of intervention in the maintenance, thus reducing costs;

- The classification as a safety fluid provides more reliability to the equipment, which can reduce losses due to failures and accidents with the occurrence of fire, which collaborate to improve the DEC and FEC indicators;

- As they withstand higher temperatures than IMO, transformers supplied with IVO tend to withstand overload work for longer;

- The use of IVO brings the environmental risk to almost zero, as its biodegradability is approximately $90 \%$, in addition to being able to be used as a raw material for the production of biofuels at the end of its useful life, unlike IMO which generates disposal costs.

In addition, Brazil is a country that has a gigantic oilseed production that tends to grow even more, making it more viable for the market and energy electric utilities to develop and implement the IVO, as well as greater investment in research that allows the appearance of further advances in this field

\section{Conclusions}

Given what has been presented, it can be said that even with high initial implementation costs, the use of IVO is feasible and quite interesting for both electric utilities and industries in the electricity sector and for those who work with products from oilseeds. In terms of efficiency and functionality, IVO's meet the normative criteria and even surpass them in some parameters discussed during the work. Based on this, it can be inferred that the long-term cost of using IVO's outweighs its cost of implementation, given the increase in the useful life of the equipment and mainly the reduction of environmental risk. In addition, in view of all the mobilization in favor of the environment that has been taking place in recent decades, the use of IVO gives the company a positive socio-environmental image, as well as promoting the creation and greater environmental awareness by the electric utilities, affiliated, staff and even the customers themselves.

Finally, the main objectives of this paper were achieved, serving as a basis for reflecting on the theme and creating new discussions on a topic current and comprehensive as this. It is worth mentioning that it is necessary to invest more in research, improvement and development of new technologies in view of the great importance of the theme, but this will only happen when there is a greater awareness of all the involved environment and the population for the need for sustainable development.

It is suggested, for future work, to carry out an in-depth analysis of costs and long-term compensation for the use of IVO in comparison to its cost of implementation.

As noted, the discussion of the use of insulating oil is not limited to engineering. Thus, it is important to expand your study in all directions, allowing great contributions to society, a fundamental role of the scientific community.

\section{REFERENCES}

[1] P. Kundur, Power system stability and control. New York: USA: McGraw-Hill Inc, 1994.

[2] V. Vittal, J. D. McCalley, P. M. Andersion, and A. A. Fouad, Power system control and stability. IEEE Press, Piscataway, 2020.

[3] J. W. D. Stevenson, Elements of Power System Analysis. McGraw-Hill Education, 1981

[4] R. Wang, Y. Zhang, and B. Jiao, "Theory research on high performance control technology of large power transformer strong oil-cooled system," in 2020 IEEE 4th Information Technology, Networking, Electronic and Automation Control Conference (ITNEC), vol. 1, 2020, pp. 2226-2230.

[5] M. Ryadi and A. Tanguy, "Field validated dynamic thermal model for power transformer insulation system assessment," in 2018 IEEE Electrical Insulation Conference (EIC), 2018, pp. 101-105.

[6] D. Pennacchi, J. B. Cavallaro, and M. L. B. Martinez, "Comparison of ac dielectric tests of insulating liquids," in 1999 Eleventh International Symposium on High Voltage Engineering, vol. 3, 1999, pp. 333-336.

[7] K. Baburao, D. Shukla, and N. Nanavati, "Depletion rate of oxidation inhibitor in hydroprocessed mineral insulating oil and naphthenic oils," in 2012 IEEE International Conference on Condition Monitoring and Diagnosis, 2012, pp. 261-264.

[8] T. Zhang, S. Wang, C. Zhang, A. Abu-Siada, L. Li, J. Han, and Z. Du, "Investigating a new approach for moisture assessment of transformer insulation system," IEEE Access, vol. 8, pp. 81 458-81 467, 2020.

[9] Siemens. (2020) Transformadores de distribuição isolados a óleo. Available in https://new.siemens.com/br/pt.html (01/07/2020). 
[10] M. Stocco, "Avaliação do potencial de aplicação de óleos vegetais como fluidos isolantes em transformadores de distribuição da rede elétrica," Master's thesis, Engenharia e Ciência dos Materiais; Universidade Federal do Paraná, Curitiba, Brasil, 2009

[11] "IEEE standard for submersible single-phase transformers: $250 \mathrm{kva}$ and smaller; high voltage $34500 \mathrm{grdy} / 19920 \mathrm{v}$ and below; low voltage $600 \mathrm{v}$ and below," IEEE Standard C57.12.23-2018 (Revision of IEEE Std C57.12.23-2009), pp. 1-23, 2019.

[12] "IEEE draft standard terminology for power and distribution transformers," IEEE PC57.12.80/D6, June 2010, pp. 1-55, 2010.

[13] "IEEE standard for general requirements for liquid-immersed distribution, power, and regulating transformers," IEEE Std C57.12.00-2015 (Revision of IEEE Std C57.12.00-2010), pp. 1-74, 2016.

[14] E. Elétrica. (2020) Transformador. Available in https // ensinandoeletrica . blogspot . com / 2016 / 03 / transformador . htmll (01/07/2020).

[15] I. Kosow, Máquinas elétricas e transformadores. São Paulo: Ed Globo, 15th edition, 1996

[16] M. Maharana, N. Baruah, S. K. Nayak, and N. Sahoo, "Comparative study of mechanical and electrical strength of kraft paper in nanofluid based transformer oil and mineral oil," in 2017 International Symposium on Electrical Insulating Materials (ISEIM), vol. 2, 2017, pp. 646-649.

[17] C. Y. Perkasa, N. Lelekakis, J. Wijaya, and D. Martin, "Investigating bubble formation in vegetable and mineral oil impregnated transformer paper insulation systems," in 2012 22nd Australasian Universities Power Engineering Conference (AUPEC), 2012, pp. 1-5.

[18] V. R. Soares, "Requirements and restrictions of vegetable tung oil as an insulating liquid for electrical distribution transformers of medium voltage," Master's thesis, Engenharia Elétrica; Universidade Tecnológica Federal do Paraná, Cornelio Procopio, Brasil, 2015.

[19] D. E. Elétrica. (2020) Funções do óleo isolante para transformador. Available in http://datalink.srv.br/artigos-tecnicos/ funcoes-do-oleo-isolante-para-transformador/ (01/07/2020).

[20] S. D. Meyers, J. J. Kelly, and R. H. Parrish, A guide to transformer maintenance. $\quad$ United States of America: TMI ${ }^{\circledR}$, Transformer Maintenance Institute, 1996.

[21] D. U. Bandara, J. R. S. S. Kumara, M. A. R. M. Fernando, and C. S. Kalpage, "Possibility of blending sesame oil with field aged mineral oil for transformer applications," in 2017 IEEE International Conference on Industrial and Information Systems (ICIIS), 2017, pp. $1-4$.

[22] M. Milasch, Manutenção de transformadores em líquido isolante. São Paulo, Brasil: Edgard Blücher, 1st edition, 1984.

[23] J. Jeong, J. An, and C. Huh, "Accelerated aging effects of mineral and vegetable transformer oils on medium voltage power transformers," IEEE Transactions on Dielectrics and Electrical Insulation, vol. 19 no. 1, pp. 156-161, 2012.

[24] H. Yu, R. Chen, X. Hu, X. Xu, and Y. Xu, "Dielectric and physicochemical properties of mineral and vegetable oils mixtures," in 2017 IEEE 19th International Conference on Dielectric Liquids (ICDL), 2017, pp. 1-4.

[25] B. E. N. A. (ANEEL), "Proposta de regulamentação do plano mínimo de manutenção e do monitoramento da manutenção de instalações de transmissão," Brazilian Electricity National Agency (ANEEL), Brazil, Tech. Rep. 0236/2013-SFE/ANEEL, 2013

[26] J. Jacob, P. Preetha, and S. Thiruthi Krishnan, "Review on natural ester and nanofluids as an environmental friendly alternative to transformer mineral oil," IET Nanodielectrics, vol. 3, no. 2, pp. 33-43, 2020.

[27] H. M. Wilhelm, L. Tulio, and W. Uhrenn, "Produção e uso de óleos vegetais isolantes no setor elétrico," Brasil Engenharia, vol. 592, pp. $120-124,2009$

[28] C. C. Claiborne and D. B. Cherry, "A status update on the use of natural ester (vegetable oil) dielectric fluids in transformers," in 74th Doble International Client Conference, 2006.

[29] L. Friedenberg and R.Santana, "Propriedades de óleos isolantes de transformadores e a proteção do meio ambiente," in Proc. of the $L X$ Simpósio Internacional de Qualidade Ambiental, 2014, pp. 1-12.
[30] R. W. Dever and S. A. Holmes, "An insulating mineral oil, a process to prepare an insulating mineral oil and a process to use an insulating mineral oil," Patent ES2 317 588T3.

[31] O. for Economic Cooperation and Development. (2011) The oecd and latin america \& caribbean. Available in http://www.oecd.org/ latin-america/countries/brazil/brasil.htm-q=301 (11/07/2020).

[32] N. A. Mehanna, A. M. Y. Jaber, G. A. Oweimreen, and A. M. Abulkibash, "Assessment of dibenzyl disulfide and other oxidation inhibitors in transformer mineral oils," IEEE Transactions on Dielectrics and Electrical Insulation, vol. 21, no. 3, pp. 1095-1099, 2014.

[33] L. R. Lewand, C. Claiborne, and D. Cherry, "Oxidation and oxidation stability of natural ester dielectric liquids," in Proc. of 77th Annual Int. Doble Client Conf., 2010.

[34] P. R. N. Ferreira, "Estudo de viabilidade técnica na utilização de óleo vegetal como agente isolante e refrigerante em substituição ao óleo mineral em transformadores de distribuição," Master's thesis, Programa de Pós-Graduação em Agroenergia, Universidade Federal do Tocantins, Palmas, Brasil, 2018.

[35] A. K. Karmaker, M. M. Sikder, and M. J. Hossain, "Investigation and analysis of electro-physical properties of biodegradable vegetable oil for insulation and cooling application in transformers," Journal of Elec Materi, vol. 49, p. 787-797, 2020.

[36] C. Olmo, C. Méndez, F. Ortiz, F. Delgado, and A. Ortiz, "Titania nanofluids based on natural ester: Cooling and insulation properties," Nanomaterials, vol. 10, 2020.

[37] D. M. Mehta, P. Kundu, A. Chowdhury, V. K. Lakhiani, and A. S Jhala, "A review on critical evaluation of natural ester vis-a-vis mineral oil insulating liquid for use in transformers: Part 1," IEEE Transactions on Dielectrics and Electrical Insulation, vol. 23, no. 2 , pp. 873-880, 2016.

[38] W. Uhren, "Aplicação de óleo vegetal como meio isolante em equipamentos elétricos, em substituição ao óleo mineral isolante," Master's thesis, Instituto de Tecnologia para o Desenvolvimento Instituto de Engenharia do Paraná, Curitiba, Brasil, 2007.

[39] S. Maneerot, K. Jariyanurat, P. Nimsanong, C. Bunlaksananusor, A. Kunakorn, and N. Pattanadech, "Studies of electrical and thermal characteristics of natural ester immersed transformer compared with mineral oil immersed and palm oil immersed transformer," in 2018 Condition Monitoring and Diagnosis (CMD), 2018, pp. 1-4.

[40] J. Fabian, B. Wieser, M. Muhr, R. Schwarz, G. J. Pukel, and M. Stössl, "Partial discharge behavior of environmentally friendly and hardly inflammable ester liquids compared to mineral oil for power transformers," in 2012 IEEE International Conference on Condition Monitoring and Diagnosis, 2012, pp. 621-624.

[41] E. Moreto and R. Fett, Tecnologia de óleos e gorduras vegetais. São Paulo, Brasil: Editorial Varela, 1998.

[42] S. Manjang, I. Kitta, and A. Ikhlas, "Voltage breakdown characteristics of transformer mineral oil with varies the composition of corn oil," in 2019 2nd International Conference on High Voltage Engineering and Power Systems (ICHVEPS), 2019, pp. 1-4.

[43] Ministério da Agricultura, Pecuária e Abastecimento, Projeç̃es do Agronegócio, Ministério da Agricultura, Pecuária e Abastecimento, Brasil, 2019.

[44] C. P. McShane, "Vegetable-oil-based dielectric coolants," IEEE Industry Applications Magazine, vol. 8, no. 3, pp. 34-41, 2002.

[45] T. V. Oommen, "Vegetable oils for liquid-filled transformers," IEEE Electrical Insulation Magazine, vol. 18, no. 1, pp. 6-11, 2002.

[46] "IEEE guide for acceptance and maintenance of natural ester insulating liquid in transformers - redline," IEEE Std C57.147-2018 (Revision of IEEE Std C57.147-2008) - Redline, pp. 1-85, 2018.

[47] D. M. Mehta, P. Kundu, A. Chowdhury, V. K. Lakhiani, and A. S. Jhala, "A review of critical evaluation of natural ester vis-a-vis mineral oil insulating liquid for use in transformers: Part ii," IEEE Transactions on Dielectrics and Electrical Insulation, vol. 23, no. 3 , pp. 1705-1712, 2016.

[48] M. Z. Villaverde and D. U. Cuadros, "Evaluation of physical-chemical characteristics of mineral oils mixed with synthetic esters," in 2019 6th International Advanced Research Workshop on Transformers (ARWtr), 2019, pp. 78-82. 
[49] S. Maneerot, P. Nimsanong, J. Siriworachanyadee, M. Leelajindakrairerk, K. Jariyanurat, and N. Pattanadech, "Dielectric response analysis of mineral oil immersed transformer, natural ester(fr3) immersed transformer, and palm oil immersed transformer,' in 2019 IEEE 20th International Conference on Dielectric Liquids (ICDL), 2019, pp. 1-4.

[50] B. Gonzalez, O. Gasca, M. Juarez, and F. Bravo, "Effect of electric field at $150{ }^{\circ} \mathrm{c}$ on the formation of corrosive sulfur in mineral transformer oil," IEEE Transactions on Dielectrics and Electrical Insulation, vol. 22, no. 5, pp. 2449-2454, 2015.

[51] CEMIG. (2019) Preservação ambiental. Available in http : / / www . cemig . com . br / pt-br / fornecedores / Documents / PoliticasdeSuprimentos/Preservaç aoAmbiental.docx (02/07/2020).

[52] C. P. de Força e Luz CPFL, "Relatório anual," Companhia Paulista de Força e Luz - CPFL, São Paulo, Brasil, Tech. Rep., 2013.

[53] G. G. T. C. de Distribuição, "Especificação para reforma de transformadores de distribuição do grupo energisa," Energisa, João Pessoa, Brasil, Tech. Rep., 2017.

[54] T. Itaipu. (2020) Ecological transformers Itaipu. Available in https //www.itaiputransformadores.com.br/transformadores/ecologicos/5 $(01 / 07 / 2020)$

[55] ASSOCIAÇÃO BRASILEIRA DE NORMAS TÉCNICAS, ABNT NBR 15422: Óleos vegetais isolantes para equipamentos elétricos - Especificação, Associação Brasileira de Normas Técnicas, Brasil, 2006

[56] K. Takahashi, K. Miyagi, and R. Hanaoka, "Negative discharge response of blend oil (ester-based insulating oil with aging mineral oil) in a non-uniform field," in 2017 IEEE 19th International Conference on Dielectric Liquids (ICDL), 2017, pp. 1-4.

[57] L. Tulio, "Estudo do envelhecimento acelerado de Óleo vegetal isolante em escala laboratorial," Master's thesis, Instituto de Tecnologia para o Desenvolvimento - Instituto de Engenharia do Paraná, Curitiba, Brasil, 2007.

[58] K. G. Devi, M. Ravindran, and S. S. Kumar, "Analysis of critical parameters of vegetable oil as an alternate dielectric fluid to minera oil," in 2016 10th International Conference on Intelligent Systems and Control (ISCO), 2016, pp. 1-5.

[59] B. T. Oliveira, "Estudo da viabilidade de substituição do óleo minera pelo óleo vegetal em transformadores de redes aéreas de distribuição de energia elétrica: estudo de caso: Cooperativa energética cocal,' Master's thesis, Engenharia Ambiental; Universidade do Extremo Sul Catarinense, Criciúma, Brasil, 2013.

[60] N. Bernard and B. Čuček, "Compatibility of mineral insulating oil with transformer construction materials," in 2017 IEEE 19th International Conference on Dielectric Liquids (ICDL), 2017, pp. 1-3.

[61] A. M. Leme and D. F. Ribeiro, "Resíduos de equipamentos elétricos descarte de óleo isolante - estudo de caso no município de rio claro," V Simpósio sobre Resíduos Sólidos (SIRS), pp. 1-5, 2017.

[62] G. Simone, "O uso de Óleo vegetal em transformadores de distribuição de energia elétrica," Master's thesis, Universidade Federal de Santa Catarina, Engenharia de Energia, Araranguá, Brasil, 2017. 